\title{
ANÁLISE DAS CONCEPÇÕES ASTRONÔMICAS APRESENTADAS POR PROFESSORES DE CIÊNCIAS, FÍSICA E MATEMÁTICA DA REDE MUNICIPAL DE SÃO JOSÉ DOS CAMPOS / SP
}

\author{
ANALYSIS OF THE ASTRONOMICAL CONCEPTS PRESENTED BY TEACHERS OF \\ SCIENCE, PHYSICS, AND MATHEMATICS OF SÃO JOSÉ DOS CAMPOS / SP \\ MUNICIPALITY
}

\author{
Edson Pereira Gonzaga ${ }^{1}$ \\ Marcos Rincon Voelzke ${ }^{1}$
}

RESUMO: Pretende-se, aqui, realizar o levantamento das concepções alternativas acerca dos conceitos básicos da Astronomia, junto aos professores da rede municipal de ensino de São José dos Campos, podendo se estender à rede estadual de ensino e estando em conformidade com documentos legais relacionados ao currículo das redes de ensino, como O Currículo do Estado de São Paulo e os Parâmetros Curriculares Nacionais (PCNs). A ideia de concepções alternativas mencionadas por Langhi (2009) será de extrema importância, pois acredita-se que, se for possível saber tais concepções antes da intervenção metodológica, será possível preparar apresentações contextualizadas e propor que os professores relacionem o que sabem com as informações apresentadas nas sessões de planetário móvel da Universidade Cruzeiro do Sul e, posteriormente, que possam discutir em um fórum de discussões, sob forma de debate, procurando estabelecer conclusões pertinentes ao tema e sua transmissão para estudantes da Educação Básica (EB). Trata-se de um estudo de caso com intervenção metodológica, levantamento quantitativo e análise qualitativa dos dados, sobre os conceitos astronômicos por meio de dois questionários, um antes e outro depois da intervenção, respeitando o período de aplicação do estudo, chama-se, aqui, de intervenção metodológica as apresentações de conteúdo no planetário móvel e as respectivas discussões.

Palavras-chave: ensino de astronomia; concepções alternativas; formação de professores.

ABSTRACT: The aim of this work is to conduct a survey of alternative conceptions about the basic concepts of Astronomy from schoolteachers in the City of São José dos Campos. This study covers the the state-run education system and complies with legal documents related to the curriculum of educational systems, such as the Curriculum of São Paulo State and the Parameters of the National Curriculum (PCN). Alternative conceptions, mentioned in Langhi (2009) as very important, were used, because it is believed that if a student can learn these concepts before the methodological intervention, it is possible to prepare contextualized presentations for teachers, and consequently students, to compare what they already know with the new information they obtain in the sessions at the digital mobile planetarium (DMP) of the Universidade Cruzeiro do Sul. Afterwards, they may discuss in a forum, in the form of debate, seeking to draw conclusions relevant to the topic, and transmitting the same to students in Basic Education (EB). This is a case study with a quantitative survey and a qualitative analysis of data on astronomical concepts collected through two questionnaires, one before and one after the intervention, respecting the implementation period of the study,- here called methodological intervention of content presentations at the mobile planetarium - and on respective discussions.

Keywords: teaching astronomy; alternative concepts; teacher education.

\footnotetext{
1 Universidade Cruzeiro do Sul. E-mails: edsonpgonzaga@gmail.com; marcos.voelzke@cruzeirodosul.edu.br.
} 


\section{INTRODUÇÃO}

Este trabalho trata de uma intervenção junto aos professores da Secretaria Municipal de Educação (SME) de São José dos Campos, sobre os conceitos astronômicos abordados na Educação Básica (EB), aos quais é proposto um estudo de caso, visando a levantar as concepções alternativas, promover apresentações em planetário móvel da Universidade Cruzeiro do Sul, um debate, e verificar os conceitos astronômicos, por meio de dois questionários, um antes e outro depois da intervenção.

Segundo Magina et al. (2010), "O papel da escola na formação de cidadãos tem sido foco de preocupações de Educadores do Brasil e do Mundo". Algumas pesquisas mostram que poucos estudantes compreendem conceitos básicos ligados à Astronomia, e que professores apresentam pouco conhecimento relacionado ao tema, o que faz refletir sobre: "Qual nível de conhecimento astronômico os professores que ministram Ciências, Física e Matemática, na rede pública de São José dos Campos, possuem?". E, também, procurar estar em conformidade com o que se pede no Currículo do Estado de São Paulo (SÃO PAULO, 2008), no Ministério da Educação e do Desporto/Sociedade Brasileira de Física (MEC/SBF) (BRASIL, 2005), nos Parâmetros Curriculares Nacionais (PCNs) (BRASIL, 1999), e nas Orientações Educacionais Complementares aos Parâmetros Curriculares Nacionais (PCNs+) (BRASIL, 2002).

A ideia é desenvolver um trabalho para responder à questão mencionada e levantar as concepções alternativas dos professores que lecionam Ciências, Física e Matemática na rede pública, por meio de sessões em planetário móvel.

Para a realização da pesquisa, pretende-se convidar todos os professores que estarão lecionando as disciplinas de Ciências, Física e Matemática para estudantes do Ensino Fundamental (EF) e Ensino Médio (EM) em 2014, independentemente da especialização de cada um.

\section{OBJETIVOS}

Pretende-se realizar o levantamento das concepções alternativas acerca dos conceitos básicos da Astronomia junto aos professores da rede municipal de ensino do município de São José dos Campos. Para isso, a ideia de concepções alternativas, mencionadas por Langhi (2009), será de extrema importância, pois acredita-se que se for possível saber as concepções que os professores possuem antes da intervenção metodológica, será possível que eles consigam relacionar o que sabem com as informações mencionadas nas sessões do planetário.

\section{JUSTIFICATIVA}

Segundo pesquisa realizada por Albrecht e Voelzke (2010), estudantes de EM não apresentavam conhecimentos científicos suficientes para o estudo dos conceitos astronômicos, os autores constataram, ainda, que não ocorria um trabalho efetivo nos EF e EM.

Não é surpreendente que os professores do EF tenham receio de levar Astronomia para a sala de aula, eles sentem-se incapazes de suprir as próprias expectativas e, consequentemente, as de seus alunos (LEITE; HOSOUME, 2007). 
Outro estudo mostra que, além da falta, quase que absoluta de conteúdos astronômicos na formação de professores dos anos iniciais do EF, a formação desses profissionais, para essa faixa etária, é inadequada, no que se refere à questão da educação científica. De acordo com Langhi e Nardi (2004):

As sugestões por parte dos professores entrevistados, em termos de conteúdos a serem trabalhados nos anos iniciais, bem como a preocupação com a metodologia de ensino, mostra que não basta que os cursos de formação inicial ou continuada privilegiem a capacitação em termos de conteúdos, divorciados das metodologias de ensino correspondentes; o grande desafio é a questão da transposição didática, ou seja, investir também, concomitantemente, no conhecimento pedagógico do conteúdo" (LANGHI; NARDI, 2004).

Os autores Langhi e Nardi (2005), Faria e Voelzke (2008) e Gonzaga e Voelzke (2011) discutem, em seus trabalhos, que a presença da Astronomia na formação de professores não deveria resumir-se em apenas conteúdos, mas deveria ser necessário que se incluísse, ainda, sugestões e orientações didáticas organizadas e definidas em função das diferentes realidades e necessidades dos professores.

A ideia em levantar as concepções alternativas dos professores ocorreu ao perceber-se a necessidade em realizar um trabalho que pudesse satisfazer as reais necessidades dos professores, de acordo com Langhi e Nardi (2005):

"[...] Acreditamos que isto só pode ser alcançado se houver uma preocupação no sentido de se investigar antecipadamente As dificuldades e necessidades dos professores envolvidos, levantando subsídios para uma posterior elaboração de atividades de formação inicial e/ou continuada que atendam suas expectativas inseridas em seu próprio contexto" (LANGHI; NARDI, 2005, p. 88-89).

Observados os problemas citados anteriormente, procura-se saber mais a respeito da preparação dos professores.

\section{METODOLOGIA}

O desenvolvimento desta pesquisa ocorrerá no município de São José dos Campos, situado na região do Vale do Paraíba, interior de São Paulo, com o apoio da Universidade Cruzeiro do Sul para a utilização do planetário móvel e com projeto apresentado junto à SME.

A realização do trabalho está prevista para o primeiro semestre de 2014. A partir da definição dos professores inscritos, pretende-se levantar as concepções alternativas por meio de pré-intervenção para todos os professores de Ciências, Física e Matemática, após levantamento das concepções, prepara-se o material tecnológico para as sessões de planetário, as quais terão durações de 40 a 50 minutos. Após as sessões previamente realizadas,

Revista Univap - Edição Especial - revista.univap.br São José dos Campos-SP-Brasil, v. 19, n. 34, nov.2013. ISSN 2237-1753 
serão discutidos os conceitos astronômicos. Para tanto, dependendo da quantidade de professores, precisa-se organizar os debates com certa organização, sendo bem provável que seja semelhante a um fórum de discussões, com exposições dos conceitos tratados e aberturas para perguntas e respostas.

Após as intervenções mencionadas e cerca de 60 dias transcorridos, serão verificados os resultados alcançados, por meio da aplicação das questões com o questionário pós-intervenção, para verificação das concepções astronômicas assimiladas, modificadas e interiorizadas.

A Tabela 1 apresenta a programação desejada para a realização do trabalho junto à Secretaria de Educação do município de São José dos Campos, ao qual, precisa-se aguardar a época de inscrição que, em geral, ocorre em meados de outubro ou novembro.

Tabela 1 - Cronograma para a Secretaria Municipal de Educação de São José dos Campos

\begin{tabular}{|c|c|c|}
\hline Programação & Início & Término \\
\hline $\begin{array}{l}\text { Inscrição do projeto } \\
\text { na SME }\end{array}$ & $\begin{array}{l}\text { Em geral, as inscrições para "Atividades } \\
\text { Articuladas aos Eixos Curriculares" são } \\
\text { realizadas em meados de } \\
\text { outubro/novembro; neste caso, em } 2013\end{array}$ & $\begin{array}{l}\text { Em meados de dezembro de } 2013, \text { a } \\
\text { Secretaria Municipal de Educação, } \\
\text { divulga os projetos para se iniciarem } \\
\text { em } 2014\end{array}$ \\
\hline $\begin{array}{l}\text { Duração das } \\
\text { atividades } \\
\text { relacionadas ao } \\
\text { projeto na SME }\end{array}$ & Fevereiro de 2014 & Novembro de 2014 \\
\hline $\begin{array}{l}\text { Questionário antes } \\
\text { das intervenções }\end{array}$ & $\begin{array}{l}\text { A aplicação do questionário ocorrerá em } \\
2014, \text { logo após o início das aulas e antes } \\
\text { das sessões do planetário móvel, estas } \\
\text { serão elaboradas em função das } \\
\text { concepções previamente levantadas }\end{array}$ & $\begin{array}{l}\text { As sessões serão tratadas em função } \\
\text { dos levantamentos realizados pelas } \\
\text { respostas do questionário pré- } \\
\text { intervenção em meados de maio de } \\
2014\end{array}$ \\
\hline $\begin{array}{l}\text { Sessões no } \\
\text { planetário móvel e } \\
\text { fórum de discussões }\end{array}$ & $\begin{array}{l}\text { Apresentam-se as concepções } \\
\text { astronômicas mencionadas neste } \\
\text { trabalho em meados de maio de } 2014\end{array}$ & $\begin{array}{l}\text { Logo após o término das sessões, } \\
\text { inicia-se o fórum de discussões para } \\
\text { promover debate sobre os conceitos } \\
\text { tratados, encerrando-se no mesmo dia }\end{array}$ \\
\hline $\begin{array}{l}\text { Aplicação de } \\
\text { questionário após a } \\
\text { pesquisa } \\
\text { propriamente dita }\end{array}$ & $\begin{array}{l}\text { Após cerca de } 60 \text { dias, aplica-se o } \\
\text { questionário pós-intervenção, serão as } \\
\text { mesmas questões do questionário pré- } \\
\text { intervenção, no entanto, os professores } \\
\text { só saberão no ato de sua realização } \\
\text { (meados de agosto de 2014) }\end{array}$ & $\begin{array}{l}\text { Ao término da pesquisa (dezembro de } \\
2014 \text { ), pretende-se divulgar os } \\
\text { resultados aos professores da } \\
\text { Secretaria Municipal de Educação de } \\
\text { São José dos Campos }\end{array}$ \\
\hline
\end{tabular}

\section{CONSIDERAÇÕES FINAIS}

Espera-se verificar, com este trabalho, as concepções alternativas acerca dos conceitos básicos da Astronomia e, caso seja possível, permitir a mudança de comportamento sobre o conhecimento científico, e, de certa maneira, influenciar na tratativa do tema Astronomia pelos professores participantes.
A busca por meios alternativos é uma maneira de tratar os conceitos astronômicos e é consenso entre outros pesquisadores que abordam a formação de professores em seus estudos (GONZALEZ et al., 2004; LANGHI; NARDI, 2004; SCARINCI; PACCA, 2006; LEITE; HOSOUME, 2007; OLIVEIRA; VOELZKE; AMARAL, 2007; ALBRECHT; VOELZKE, 2010; FARIA; VOELZKE, 2008; GONZAGA; VOELZKE, 2011).

Revista Univap - Edição Especial - revista.univap.br 


\section{REFERÊNCIAS}

ALBRECHT, E.; VOELZKE, M. R. Teaching of astronomy and scientific literacy Journal of Science Education, v. 11, p. 35-38, 2010.

BRASIL. Ministério da Educação. Secretaria da Educação Média e Tecnológica. Parâmetros Curriculares Nacionais: ensino médio. Brasília-DF: MEC, 1999. 364 p.

BRASIL. Ministério da Educação. Secretaria da Educação Média e Tecnológica. PCN+ Ensino Médio: orientações educacionais complementares aos parâmetros curriculares nacionais: ciências da natureza, matemática e suas tecnologias. Brasília-DF: MEC, 2002. 244 p.

BRASIL. Ministério da Educação. Sociedade Brasileira de Física, MEC/SBF. Ensino de Física: reflexões. Brasília-DF: UnB., 2005. p. 1-3.

FARIA, R. Z.; VOELZKE, M. R. A introdução de astronomia básica para estudantes de $5^{\text {a }}$ e $6^{\underline{a}}$ séries do ensino fundamental. Boletim da Sociedade Astronômica Brasileira, v. 28, n. 1, p. 117-117, 2008.

GONZAGA, E. P.; VOELZKE, M. R. Análise das concepções astronômicas apresentadas por professores de algumas escolas estaduais. Revista Brasileira de Ensino de Física, v. 33, n. 2, p. 2311(1)-2311(12), 2011.

GONZALEZ, E. A. M. et al. A astronomia como ferramenta motivadora no ensino das Ciências. In: CONGRESSO BRASILEIRO DE EXTENSÃO UNIVERSITÁRIA, 2., 2004, Belo Horizonte-MG. Anais... Belo Horizonte: UFMG, 2004. p. 7.

LANGHI, R. Astronomia nos anos iniciais do ensino fundamental: repensando a formação de professores. 2009. 370 f. Tese (Doutorado) Universidade Estadual Paulista, Faculdade de Ciências Bauru, Bauru, 2009.
LANGHI, R.; NARDI, R. Um estudo exploratório para a inserção da astronomia na formação de professores dos anos iniciais do ensino fundamental. In: ENCONTRO NACIONAL DE PESQUISA EM ENSINO DE FÍSICA, 9., 2004. Jaboticatubas-MG. Anais... JaboticatubasMG: COLTEC-UFMG, p. 1-13, 2004.

LANGHI, I. R.; NARDI, R. Dificuldades interpretadas nos discursos de professores dos anos iniciais do ensino fundamental em relação ao ensino da astronomia. Revista Latino-Americana de Educação em Astronomia - RELEA, n. 2, p. 75-92, 2005.

LEITE, C.; HOSOUME, Y. Os professores de ciências e suas formas de pensar a astronomia. Revista Latino-Americana de Educação em Astronomia - RELEA, n. 4, p. 47-68, 2007.

MAGINA, S. et al. Concepções e concepções alternativas de média: um estudo comparativo entre professores e alunos do ensino fundamental. Educar em Revista, n. 2 (esp), p. 59-71, 2010.

OLIVEIRA, E. F.; VOELZKE, M. R.; AMARAL, L. H. Percepção astronômica de um grupo de alunos do ensino médio da rede estadual de São Paulo da cidade de Suzano. Revista Latino-Americana de Educação em Astronomia - RELEA, n. 4, p. 79-99, 2007.

SÃO PAULO (Estado). Secretaria de Estado da Educação. Coordenadoria de Estudos e Normas Pedagógicas. Proposta Curricular do Estado de São Paulo: São Paulo: SEE; CENP, 2008. $60 \mathrm{p}$.

SCARINCI, A. L.; PACCA, J. L. A. Um curso de astronomia e as pré-concepções dos alunos. Revista Brasileira de Ensino de Física, v. 28, n. 1, p. 89-99, 2006. 